of increased capacity was now no higher than ten years ago, in spite of the increase in cost of materials and labour. As regards nuclear power, the cost of the Bradwell and Berkeley stations would be about three times that of a coal-fired station, but that of Hinkley Point should be about 2.5 times, and it was now calculated that this would be about $£ 120$ a kilowatt. By the nineteen-sixties the nuclear plant should be marginally more economical than conventional plant. There had already been a reduction at the rate of about 3 million tons of coal a year in the amount of oil to be used for power stations in the early nineteen-sixties, and the Government believed that the demand of the power stations for coal would rise throughout the next seven years.

Lord Mills, the Minister of Power, added a few further details in moving the second reading of the Bill in the House of Lords on March 3. Since some of the existing plant will not be fully operated, and because of obsolescence, the net increase in output capacity in England and Wales will be just over 10 million kilowatts, while the South of Scotland Electricity Board expects to commission more than 1 million kilowatts of new plant and the North of Scotland Hydroelectric Board about 460,000. The load factor is expected to increase to $49 \cdot 2$ per cent by 1964-65, and Lord Mills hoped that substantial improvements could be made in the methods of transmission and distribution so as to reduce the need for overhead lines in the countryside. The Boards had very much in mind the need to find means of diminishing the impact of their lines on amenities. Apart from the hydroelectric plant in the north of Scotland, practically all this new plant would be coal-fired or nuclear, and it was estimated that nuclear power could absorb nearly 47 per cent of the $£ 1,100$ million which the Central Electricity Board proposed to spend on power station construction. The nuclear power programme for 1964 onwards had not yet been decided, but apart from water-power we intended to rely in the long-term on coal and on nuclear power : less than 4 per cent of the investment in power stations proposed over the next seven years represented oil-fired plant.

These statements form a background to the third White Paper* on capital investment in the coal, electricity and gas industries, which is limited to the years 1957-59. Actual expenditure in 1957 was $£ 434.7$ million, compared with $£ 438.9$ million and $£ 524.7$ million approved for 1958 and 1959 , respectively. Of these figures, $£ 240 \cdot 2$ million, $£ 241 \cdot 3$ million and $£ 303.5$ million are for the Electricity Council and Boards in the respective years: actual expenditure in 1958-59 is estimated to have been $£ 258.5$ million, of which $£ 106 \cdot 5$ million was for conventional power stations and $£ 38 \cdot 0$ million for nuclear power stations. The corresponding figures in the approved 1959 60 programme are $£ 117.5$ million and $£ 57.0$ million, and payments in respect of the nuclear power stations at Bradwell, Berkeley and Hinkley Point will reach their peak during the year. The North of Scotland Hydroelectric Board's programme of capital expenditure of $£ 10$ million on generation for 1959 is mainly for hydroelectric schemes at present in hand, while that of the South of Scotland Electricity Board of $£ 16 \cdot 2$ million on generation in 1959 is almost entirely accounted for by the nuclear power station at Hunterston and the coal-fired station at Kincardine. * Capital Investment in the Coal, Electricity and Gas Industries.
Pp. 8. (Cmnd. 713.) (London: H.M. Stationery Office, 1959.) 6d. net.

\title{
BATHYSCAPHE F.N.R.S. III
}

$\mathrm{O}$ NE of the greatest recent advances in methods of deep-sea research is that of direct observation under water by photography, television and the human eye. The latter had already been shown possible before the Second World War by Otis Barton and William Beebe in the cable-dependent bathysphere.

In 1939, Prof. Auguste Piccard and Prof. Max Cosyns gained the support of the Fonds National de la Recherche Scientifique Belge (F.N.R.S.) to build their free-navigating bathyscaphe, but owing to the War its construction was delayed. The first tests were made in December 1948 off Dakar in the vessel which was entitled F.N.R.S. II, the Piceard-Cosyns stratosphere balloon being F.N.R.S. T. A depth of $1,380 \mathrm{~m}$. was achieved without passengers. Although improvements were needed, the possibilities of the bathyscaphe were proved, and in October 1950 an agreement was signed between the Belgian Fonds National de la Recherche Scientifique, the French Navy, and the French Centre National de la Recherche Scientifique for the construction by the French Navy at Toulon of F.N.R.S. III, using the sphere of bathyscaphe F.N.R.S. II. This new vessel was put into the water in June 1953 and Capitaine de corvette G. Houot was placed in command with Ingénieur du génie maritime P. Willm to assist. Together they carried out a series of tests ending off Dakar in February 1954 when they reached a depth of $4,050 \mathrm{~m}$.
In May 1954 the French Centre National de la Recherche Scientifique obtained permission from the Navy to equip and use F.N.R.S. III for scientifie purposes. A management committee was appointed under the stimulating presidency of Prof. Louis Fage. The first dive was made on April 18, 1954, at a position 25 miles south-west of Dakar to a depth of $850 \mathrm{~m}$. with Prof. Th. Monod as the scientist on board; this was quickly followed by a dive to 1,400 $m$. Thereafter a certain number of dives have been made each year with Commandant Houot on board, accompanied by a qualified naturalist. By the end of 1957, twenty-eight dives had been made to depths between $130 \mathrm{~m}$. and $2,290 \mathrm{~m}$., eighteen of which were deeper than $1,000 \mathrm{~m}$. Eight distinguished and courageous biologists took part. Their names are given here, together with the number of dives each made, because they should be remembered as pioneers of this new era of marine research : Prof. Th. Monod, Dakar (2) ; Prof. J.-M. Péres, Marseilles (9); J. Picard, Marseilles (4) ; Prof. Fr. Bernard, Algiers (3) ; J. Furnestin, Paris (1) ; Prof. Dubuisson, Liège (1); G. Trégouboff, Villefranche (6) ; M. Ruivo, Lisbon (1). Dives were made in the Mediterranean and the Atlantic. F.N.R.S. III is equipped with apparatus for recording at any time the depth, temperature and pressure; it has equipment for collecting water samples with contained microplankton; and it has powerful light projectors and automatic cameras. It 
does not yet possess means for efficient capture of larger planktonic or bottom-living animals, but observations can be supplemented by collections made by the accompanying vessel with pelagic nets and trawls.

A number of individual accounts have already been published, but a general review of the principal results obtained up to the end of 1957 has now been made available*. Since much of the biological information must be obtained by direct observation, it is essential that the accompanying biologist should be experienced, and that he should have a thorough knowledge of the fauna he is to investigate so that he may be able to identify as many organisms as possible. The more dives he makes also the more competent will he become at observing. Given these requirements there is no doubt that the results obtained will be of

* Annales de l'Institut Océanographique fondées par S.A.S. Albert ler Prince de Monaco. Publiées sous la direction de Louis Fage Nouvelle Série. Tome 35, Fasc. 4 et dernier: Resultats Scientifiques des Campagnes du Rathygeaphe F.N.R.S. III, 1954-1957. Pp. 235 great value since the depth, temperature and light conditions can be known exactly. Indeed, most interesting information is already forthcoming on the distribution in depth and abundance of some plankton animals. The occurrence of coccolithophores in considerable numbers at great depths has also been established. A noteworthy feature is the abundance of particles in suspension at different depths. It is now known that the subsistence of the bottom sediments is reasonably firm. Numerous small mounds on the sea bottom are common, but prolonged watching has so far revealed no occupants. Unusual habits and movements of deep-sea fish have been observed. The presence of slow currents has been shown by particles drifting along the bottom.

There is no doubt that the value of the bathyscaphe as a tool in marine research has been proved by French scientists, to whom all honour is due ; and as a result new models to attempt greater depths are on the way.

F. S. RUSSELI

\section{ALFVEN WAVES IN A GAS DISCHARGE}

\section{By D. F. JEPHCOTT*}

Atomic Energy Research Establishment, Harwell, Berks

$I^{N}$ 1942 Alfvén ${ }^{1,2}$ predicted the possible existence of magnetohydrodynamic waves, which may be regarded in the simplest case as transverse oscillations of magnetic field lines carrying with them a surrounding inviscid perfectly conducting fluid.

The velocity of propagation is given by :

$$
V^{2}=\frac{\mu H^{2}}{4 \pi n M}
$$

where $H=$ magnetic field intensity ; $n=$ number of particles/cm. ${ }^{3} ; M=$ mass of particle.

Alfvén's theory strictly applies only to waves in an incompressible fluid, but it can be extended to a compressible fluid (for example, an ionized gas) for the case of waves of small amplitude. A further restriction is that the frequency should be small compared with the ion cyclotron frequency ${ }^{3}$.

Previous experimental work has been carried out in liquid conductors ${ }^{4-6}$, and standing Alfvén waves have been reported in some gas discharges 7,8 .

Our experiments have been carried out using toroidal gas discharges of $10 \mathrm{k}$.amp., and $200 \mu \mathrm{sec}$. duration, in monatomic gases at initial pressures of about $100 \mu$, and with axial $\left(B_{z}\right)$ fields in the range 3-14 k.gauss. Under these conditions, the current density was nearly constant across the area of the torus (except close to the walls) and the discharge sufficiently quiescent for satisfactory signals to be obtained from magnetic probes.

Fig. 1 illustrates the method used for exciting the waves and measuring their velocity.

When the gas current had reached its peak value, the condenser $C$ was discharged via the spark gap $S$ through the exciter conductors $A$ and $B$, which were close to the outer wall of the torus. The condenser circuit oscillated at $260 \mathrm{kc}$./s., imposing perpendicular components on the main field, and resulting in torsional oscillations about the circular axis of the torus.

* On attachment from Hawker Siddeley Nuclear Power Co.
Oscillations of the order of 10 gauss in amplitude were picked up by the magnetic probe 2 and were found to be delayed relative to the signal from probe 1 which recorded the direct exciting field. No oscillations were observed with $B_{z}=0$, and the amplitudes always increased with $B_{z}$ over the working range. Velocities were calculated after a small correction had been made for the measured time-lag of the perturbing field at $D(d=0)$ in the plasma, relative to the direct vacuum field of the conductors.

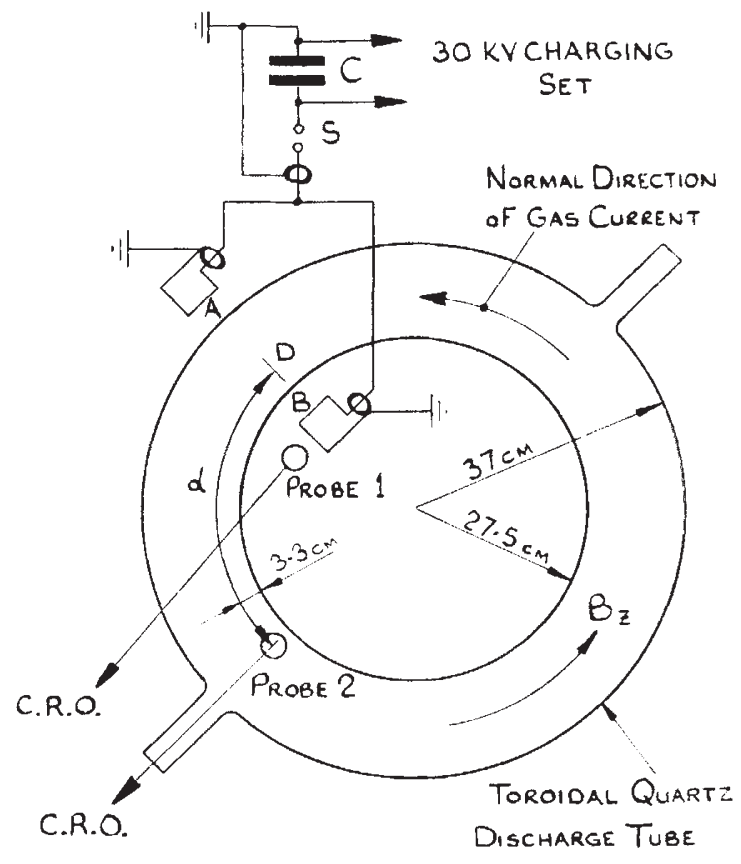

Fig. 1 